\title{
Alevi İnancında Can, Ruh Kavramı ve Nefsin Eğitimi
}

\section{Education of the Nafs in the Context of Sprit and Soul in Alawi Faith}

\section{İbrahim Gül ${ }^{*}$}

\section{Öz}

Ruh, can ve nefs sözcükleri insanın zihnini meşgul eden kavramlardır. Bu konuda bazı araştırmalar yapılmış olmasına rağmen bu kavramların mahiyeti tam olarak anlaşılmamıştır. Bu çalışmanın amacı, ruh, can ve nefs kavramlarını ele alarak açıklamaktır. Bu araştırmada söz konusu kavramların İslam-Alevi inancına ve kaynaklarında nasıl ele alındığına ilişkin açıklamalara yer verilmiştir. Bu amaçla önce bazı Alevi klasikleri incelenmiştir. Bu yönüyle düşünüldüğünde, araştırma kaynak taramaya dayalı bir çalışmadır. Çalışmadan elde edilen bilgilere göre, ruh ve can karmaşık kavramlardır. Bu konuda insana çok az bilgi verilmiştir. Can ve ruh çoğu zaman birbirinin yerine kullanılan kavramlardır. Nefs, insanı kötü işler yapmaya sürükleyen duyguları ifade eden bir kavram olarak görülmektedir. İnsan, aklını ve iradesini kullanarak nefsin isteklerine engel olabilir. Yani bir bakıma her insan nefsini eğitebilir. Nefsin eğitimi ise daha çok tasavvufun konu alanına girmektedir. Alevi inancında nefsini eğiten insan, kâmil insan olarak bilinir. Kamil insanın hiçbir zaman canı ölmez, ölen onun bedenidir. Bu çalışmada, Alevi klasiklerinde can, ruh ve nefs kavramlarına bir açıklık getirilmeye çalışılırken bir bakıma İslam- 
Sünni mezhepleriyle de bir karşılaştırılması yapılmıştır.

Anahtar sözcükler: Alevi inancl, can, ruh, nefs, nefsin eğitimi

\begin{abstract}
The concepts spirit, soul and nafs have occupied the human mind for very many centuries. Despite the extensive literature devoted to them, the essence of these concepts has yet to be fully and thoroughly comprehended. The purpose of this study is to explore the concepts spirit, soul and nafs within the context of IslamicAlevi faith and sources. To this end, a number of Alevi classics have been studied. In this respect, this article is based on literature review. It can be inferred from the findings of this study that spirit and soul are rather complex concepts, and that far too little information has been given to human beings in religious sources as to the essence and nature of these concepts. The words spirit and soul are often used interchangeably, and nafs refers to the unfavorable feelings human beings have that prompt them to commit errors, sins, and crimes. They can, however, resist the urges of the nafs by virtue of their reason and will. In other words, each and every person is capable of training his/her nafs, as taught thoroughly by Islamic mysticism. In the Alevi belief system, as in Islamic mysticism, a person who has completed all the stages of this training is said to have become the perfect human being (insan-1 kamil). Such a person's soul never dies, even though his/her body may cease to exist. While exploring the concepts of spirit, soul, and nafs in Alevi classics, this study also draws a comparison between the way these concepts are perceived by the Alevis and those adhering to the Islamic-Sunni sects.
\end{abstract}

Keywords: the Alevi faith, spirit, soul, nafs, training of the nafs

\title{
Extended summary
}

Spirit, nafs and soul are mysterious concepts that need to be emphasized in Alevi Faith. In the research, these concepts was tried to be clarified. In this respect, the source scanning method is used in the research. First, the concepts of spirit, nafs and soul were explained, and then it is tried to clarify how these concepts were used in the Alevi Faith. Although there are some studies on the subject, studies on how these concepts are used in Alevi Faith are limited.

It is known that these interchangeable concepts sometimes have different meanings. Spirit means life and vitality. Philosophically, the soul is the life force of the body. Little is known about the soul. Spirit is the subject of psychology as well as medical science. There are different opinions about whether life and soul are the same. The soul is also defined as cosmic consciousness. According to this view, there is a soul at the center of every substance. The soul carries out life activities in humans. There are souls in plants, animals and humans. Many theologias use the concept of soul and spirit in the same sense. Nafs contains a different meaning according to these. The nafs (ego) is seen as the source of evil and it is stated that it should be educated.

The concepts of spirit, soul and nafs are explained in different ways in some sources. In Hacı Bektaş Veli's Makalat, the concepts of soul, spirit and nafs are mentioned in many 
places. There are four types of souls in Makalât. Another study that talks about these concepts is Alevi Buyruğu There is no discrimination between men and women in the Alevi Buyruğu An important explanation here is that Allah created the Nur of Muhammad and Ali from his Own Nur. God created many beings before he created Adem. He destroyed them and created Adem. In the Qur'an, the concept of soul is used instead of life. It is stated in the Qur'an that the word spirit means knowledge. One of the places where the concept of spirit is frequently mentioned is the Alevi-Bektashi poems. In the poems of people known as the Yedi Ulu Ozan, the concepts of spirit, soul and nafs are mentioned. In Alevi Cem rituals, the concept of spirit used for people regardless of gender means not to distinguish between men and women.

There is no need to educate soul and spirit. The nafs explains the emotions that lead the individual to evil. Therefore, there is a need to train the ego or nafs. In the Alevi faith, the education of the soul can be done with the help of a pir (master). Pir is the one who trains the disciple and keeps him from sins. He is the person who shows people the right way. Alevi persons are people in the way of Sufism. The way to educate the soul is to be in the path of Sufism. Alevi persons try to educate themselves by taking full moral control of selfish desires (having their hands, tongue and waist). As in Islam, the struggle against the nafs has an important place in the belief of the Alevi faith.

Cem ritual has an important place in educating the nafs. In the Cem ritual, the pir advises the attendees and enlightens them. Yedi Ulu Ozan poets are read in the cem ritual. People who listen to these poems infer a meaning from them. They improve themselves emotionally. Each Alevi takes into account the provisions in the Alevi Buyruklar1. Tries to abide by these rules. In the Cem ritual is no discrimination between men and women. People who attend the Cem ritual see themselves as mature people. In this respect, it is not a problem for men and women to worship together.

It can be said that spirit and soul provide movement to the body. There is not much explanation about the soul in the scriptures. The concepts of life and soul can be explained by computer analogy. In this case, spirit is considered a hardware; the soul can be thought of as software. Just as computer software is controlled by users, the human spirit can also be controlled by God. However, it is simplifying to explain a person's soul and spirit with a machine analogy. On the contrary, the concepts of spirit, soul and ego are more complex than a machine. It is not easy to fight with nafs. The education of the nafs is an indication that people are tested in this world. In this study, it was concluded that the self-educating nafs in Alevi faith passes through Sufism

\section{Giriş}

Can, farklı inançlarda sıklıkla kullanılan bir kavramdır. Can çok defa gönül (dil) ile birlikte zikredilir. Can ile çoğunlukla benzer anlamda kullanılan bir başka kelime ise ruh sözcügüüür. Bu kelimeler bazen birbirinin yerine de kullanılmaktadır. Ölen birisi için, ruh kuşu kafesten uçtu ifadesi kullanılmaktadır. Uçan can mıdır yoksa ruh mudur? Yoksa bu iki kelime aynı anlama mı gelmektedir? 
Alevi inancında can kelimesi farklı anlamlarda kullanılmaktadır. "Gelin canlar bir olalım." veya bir gruba hitap edilirken, "merhaba canlar" gibi ifadeler kullanılmaktadır. Bu iki örnekte can, cinsiyet ayrımı gözetmeme, yani kadın-erkek herkesi ifade etme anlamında kullanılmıştır. Alevi deyişleri içinde can sözcüğü yoğun olarak geçmektedir. Bu çalışmayla farklı manalarda kullanılan can, ruh ve nefs kavramlarına açıklık getirilmeye çalışılmıştır.

Literatürde ruh, can ve nefs kavramlarıyla ilgili çalışmalara bakıldığında, bu konuda bazı araştırmaların yapılmış olduğu görülmektedir. Taş'1n (1994), Tasavvufta Ruh Kavramı, Ögke'nin (1994), Kur'an'da Nefs Kavramı, Cengil'in (1996), Kur'an-ı Kerim'deki Nefs Kavramına Psikolojik Açıdan Bir Yaklaşım, Hallaçi'nin (2013), Plotinus ve Fârâbî'de Ruh/ Nefs Kavramı, Kantik'in (2015), Tefsîru'l-Ceylânî'de Nefs Kavramı, Osman'ın (2017), Gazzali'nin Ahlâk Felsefesinde Nefs Kavramı, Çebi'nin (2019), İslâm Kültüründe Nefs Kavramı başlıklı çalışmaları bunlardan bir kaçıdır. Ancak bu çalışmalarda söz konusu kavramlar daha çok İslam-Sünni inancına göre ele alınarak incelenmiştir. Alevi inancında ruh, can ve nefs kavramlarına ilişkin araştırmaların ise sınırlı olduğu görülmektedir.

\section{Can, ruh ve nefs kavramları}

$\mathrm{Bu}$ kavramlar hakkında kısa bir açıklama yapıldıktan sonra konuya girmenin doğru olacağ1 düşünülmüştür.

\subsection{Can kavramı}

Can, yaşama ve hayat anlamına gelmektedir. Sözlükte, insan ve hayvanlarda yaşamayı sağlayan ve ölümle vücuttan ayrılan madde dışı varlık (TDK, 2017) olarak tanımlanmaktadır. $\mathrm{Bu}$ kelime bazen farklı anlamlarda da kullanılmaktadır. Bazılarına göre can, ruh demektir (Kaptan, 2014). Can kelime karşılığı olarak ruh, hayat, diride olan kudret/kuvvet gibi pek çok anlama gelir. Aleviler kendi cem/ibadet ayinlerinde, dişi-erkek, sen-ben ayrımını ortadan kaldırıp insanı öne çıkarmak için bu kavramı kullanırlar (Seyyid Hakkı, 2017). Can kavramı, tasavvuf literatüründe "nefs, ruh, ilâhî nefes ve tecelli” karşılığında kullanılır (Özkan, 2010: 358). Eflatun, insanın can ve ruhunu tam ve denenmemiş fikirlerin en yüksek semasından gelen şeyler olarak kabul eder (Bayrakl1, 1986: 188). Başka bir görüşe göre, yeryüzünde ve evrende cansız ve bilinçsiz tek bir şey mevcut değildir. İnsan beyni beş duyuya bloke olduğundan kendisinden gayrisini canlı olarak kabul etmez (Ahmet Hulusi, 2014: 12-13). Bu nedenle sadece belli varlıkları canlı kabul eder.

\section{2. Ruh kavramı}

Ruh, varlığı kabul edilen ancak mahiyeti tartışılan bir kavramdır. Sözlükte, dinlerin ve dinci felsefelerin insanda vücuttan ayrı bir varlık olarak kabul ettiği öz, tin, can kuşu; felsefi anlamda, bedeni etkin kılan canlılık ilkesi, bedenin hayat gücü (TDK, 2017) olarak tanımlanmaktadır. Kur'an-1 Kerim'de rûh sözcüğü farklı anlamlarda kullanılmıştır: Bunlar sırasıyla vahiy, kuvvet, sebât ve yardım, Cebrâil, insanın mânevî cevheri ve özü ve Meryem 
oğlu Mesih manasında (Altıntaş, 201: 15). İbni Sina'ya göre ruh, bedenden ayrı bir manevi cevher (enerji) olup, bedeni bir araç olarak kullanır (Çelik, 2017). Ruh, huve, cevherun, basiytun ve mücerredün gibi değişik kelimelerle ifade edilmiştir (Tomor, 2016). İnsanlar Hz. Muhammed'e ruhu sorduklarında, gelen ayette (İsra 85), "Ruh, Rabbimin emrindendir. Size ilimden pek az bir şey verilmiştir” buyurulmuştur. Böylece ruh varlığg tasdik edilmiş fakat mahiyeti açıklanmamıştır (Başar, 2006).

Can ile ruhun ayrı bir varlık olduğu konusu tıp biliminin de inceleme alanına girmektedir. İnsanın yaratılış safhaları incelendiğinde, nutfe (döllenmiş yumurta), Alaka (rahmin çeperinde tutunan hücreler topluluğu), Mudğa (ceninin şekillenmeye başladığı), azm (belli belirsiz şekil) lahm (kemik ve kemiklere et giydirilmesi) safhaları olarak sıralanmaktadır. $\mathrm{Bu}$ safhaları tamamlayıp insan şeklini aldıktan sonra cenine ruh üflenir (Ucatlı, 2009, s. 20). Kur'an'a göre, insana ruhun üflendiği zaman 16. haftadır (Mü'minûn/14). Bir hadiste nutfenin üzerinden 42 gece geçince Allah'ın ona ruh üflemek için bir melek gönderdiği belirtilmektedir (Müslim, 1998: 1060).

\subsection{Can ve ruh ilişkisi}

Can ve ruh ile ilgili kısa bir açıklama yapıldıktan sonra, ruh üzerinde yapılan tartışmalara da kısaca değinmek gerekir. Bilim insanlarının araştırdığı ve merak ettikleri konular arasında, ruhun tek mi yoksa çok mu olduğu, ne zaman yaratıldığı ve insan bedeninden ayrı bir varlık olup olmadığı hususu yer almaktadır. Bu sorulara doyurucu bir cevap bulunmamasının nedeni, Kur'an ayetlerinde belirtildiği gibi, insana bu konuda çok az bir bilgi verilmesinden kaynaklanmaktadır. Yine de insanoğlu ruh ve can gibi konuları merak etmekte ve bunlar üzerinde düşünme ve yorum yapma ihtiyacı hissetmektedir.

Mevlânâ hazretleri, "Beden ruh vasitasiyla hareket eder, fakat siz ruhu göremezsiniz: Ruhu bedenin hareketleriyle bil” (Mesnevi IV,155) buyurmuştur. İmam-1 Gazali’ye göre, ruh tektir. Cesetlere taalluku hâlinde birtakım çeşitli vasıflar kazanır ve böylece çoğalmış olur. Ahmed Hulusi, Gazali'nin (2014) bu görüşüne katılmakla birlikte, ruhu bir enerji olarak görmektedir. Enerjinin varlığını Allah'ın kudreti oluşturur. Ruh bir başka anlatımla "kozmik bilinç” olarak nitelenir. Her nesnenin yapısındaki bilinç, onun özünü oluşturan aslı ve orijini olan ruh içinde mevcuttur. Bigalığlu (2009), ruhu, insanı diğer canlılardan ayıran, ona insan olma özelliği kazandıran metafizik (fizik ötesi) bir enerji formu olarak değerlendirir. Ruh, insan bilincine ilk girdiğinde şekilsiz sade bir biçimdedir ve üzerinde insan olma özelliklerini taşıyan bir program mevcuttur. Bu program sayesinde hem bilinç hem de beyin programlanır.

\subsection{Can ve ruh kavramına maddesel bir bakış}

Bilgisayar temel olarak, donanım ve yazılım olmak üzere iki ana bölümden oluşmaktadır. Donanım (Hardware), bilgisayarın fiziksel yapısını oluşturan parçalardır. Yazılım (Software), donanımsal parçaların çalışma ve işlemleri gerçekleştiren ve kullanıcı ile iletişimini sağlayan yapıdır (Acar, 2018). Bilgisayarın donanımı insan bedenine benzetilebilir. $\mathrm{Bu}$ donanım 
elektrik enerjisi olmadan çalışmaz. Donanıma elektrik verme, insan bedenine can verme olarak düşünülebilir. Ancak bir bilgisayar donanım olarak çalışsa bile, yazılım olmadan hiçbir işe yaramaz. İşte insan bedenindeki ruh bilgisayarda yazılımlara karşılık gelmektedir. Bilgisayarın işletişim sistemi, matematiksel işlemler ve diğer işlemleri akla karşılık gelecektir. Yazılım bilgisayara yüklendiğinde onun bir takım işlemler yapmasına imkân sağlar. Tek bir yazılım farklı bilgisayarlara yüklenerek hepsini çalıştırabilir. Bu örnek tek bir ruh ile bütün insanların idare edilebileceğini gösterir. Yazılımlar iyi veya kötü amaçla kullanılabilir (Yani ruh ile nefis örneğinde olduğu gibi). Kişiler bu programları kullanma konusuna özgür bırakılmışlardır. Elektrik kesildiğinde (yani bedenden canın çıktığı gibi) yazılımlar çalışmaz (yani ruh da gider). Programlar uzaktan kontrol edilebilir. Yani onu üreten firmalar onları uzaktan kontrol edebilirler. Bu benzetmeyle, insanların ruhları da Allah tarafından kontrol edilir. Mutlak güç sahibi Allah için bunu yapmak zor bir iş değildir.

\subsection{Nefs kavramı}

Can ve ruh ile ilgili başka bir kavram da nefistir. Bağçeci’ye (1987, s. 179) göre nefs, insanda canlılık faaliyetleri, beş duyu, şehvet, hırs, nesli muhafaza ve hayatı koruma gibi bedenin ihtiyaçlarını idare eder. Bu nefis hayvanlarda da vardır. Hayvani nefis canlılık faaliyetlerine ait istekleri yerine getirir. Yani haz ve zevk prensipleriyle hareket eder. İyi huy ve vasıflara mahal ruh, kötü huy ve vasıflara mahal nefistir (Kuşeyri, 197: 183). İbni Sina nefsi üç kısımda görür: Bitkisel nefis (beslenme ve üreme işlevleri), hayvan nefsi (duyumlama, hayal ve irade), insan nefsi (akletme yetisi). İnsan nefsi, kavrama ve düşünme fiillerini meydana getirir (Atay, 1997: 17). İnsan ruhu bedende olduğu müddetçe beden diri olur. Ruh bedenden bağıntılı olarak ayrılırsa, uyku halindedir. Bu ayrılma tamamen olursa, bedenin ölmesi anlamına gelir.

Kur'an-1 Kerim'de beden ve ruh ayrımı yapılmaksızın insanın tamamına nefs denilmiş ve Kur'an'da nefs, birey, dönüşlü zamir, tür, zihin ve kalp anlamında olmak üzere beş anlamda kullanılmıştır (Merdin, 2014). "Her nefis ölümü tadıcıdır... (Ali İmran/185)" ayetinde de nefs kelimesi can anlamında kullanılmıştır. Böylece ölen birisi üçüncü boyuttan dördüncü boyuta geçer ve artık bundan sonra dünya boyutuna geri dönemez (Arkut, 2014). Ruh-nefis çatışmasında, ruhsal üstünlüğü sağlamayı başaranlar (kalp gözü açık olanlar) ruh hakkında bizden daha fazla bilgiye sahip olabilirler (Tomor, 2016).Allah insanı sınamak için nefs vermiş ve nefsin belli miktarda ihtiyaçlarının karşılanmasını helal kılmıştır (Kıray, 2013).

Kur'an'da nefs, emmâre, levvâme, mülheme, mutmainne, râzıyye, merzıyye ve kâmile gibi sıfatlarla sayılmıştır. Sûfilere göre nefs, şerrin kaynağı, kötülüklerin temelidir ve mutlaka terbiye edilmesi gerekir (Hucviri, 1982: 309). Nefsin istek ve arzularına zikir ve yoğun ibadet ile karşı koymak gerekir. Buna göre kişi sabırlı olmalı, nefsin açgözlülüğünden uzak durmalı ve nefsin aldatıcı telkinlerine karşı koyabilmelidir (Sivaslı, 2016).

Sufilere göre, mürşid-i kâmile tâbi olmadan nefsi dizginlemek oldukça zordur. İnsan diğer mahlûkattan faklı olarak iki ruhtan ibarettir. Birisi candır ki cesetle son bulur. Diğeri Cenabı Hak’tan gönderilen keyfiyetli ruh yani, ruh-i sultanidir. Öyleyse insan nefiste ölüp, 
ruhta dirilmeye çalışmalıdır. 'Ölmeden evvel ölünüz” sırrının tecellisi budur, yani nefsin hevasını öldürmektir (Nurefşan, 2011). Alevi inanç önderi olan mürşitler insana kendini bildirmeli, ilm-i câvidanı öğretmelidir" (Özdemir, 2017: 133).

\section{Makâlât'ta can, ruh ve nefs}

Makâlât Hacı Bektaş Veli’nin önemli eserlerinden biridir. Bu eserin bazı bölümlerinde can ve ruh kavramı geçmektedir. Bu konu muhipler ile ilgili bölümde anlatılmaktadır: $\mathrm{Ne}$ zaman ki bir veli, ey Rabbim dese, yüce Allah'ın lebbeyk demesiyle bunların sedası arşta birleşir. Bu ikisinin arasından bir nur çıkar ve o nurun aydınlığından yedi kat gök altında yüz bin renk çiçek biter. Bunların arasında "reyhan gülü” derler bir çiçek vardır. O velilerden birisinin ölüm vakti gelse o çiçeği ona koklatırlar ve canını aşk ile alırlar. O veli canını teslim ettiğini asla bilmez (TDV, 2007).

Tarikat kapısı can makamı ile son bulmaktadır. Öyleyse can cana değse, şevkle hareketine şaşılmamalıdır. Can Allah'ın insana bahşettiği ilahi bir nasiptir. Kime değdiği belli olması gerekir (TDV, 2007).

Marifetin beş giysisi ilham, anlayış, aşk, şevk ve muhabbettir. Bu giysiler cana değdiğinde can dirilerek akla uygun gelir ve geleni gideni anlamaya başlar. Her şey can ile dirilir yani can, marifetle dirilir. Marifetli canın erenler canı, marifetsiz canın hayvan canı olduğu söylenebilir. Öyle ki âşıkların teni ölür ama canı ölmez (TDV, 2007). Seyyid Saaddin buyurur ki:

"O can ki

Kıymetini aşktan alır

Bütün canlar ölünce

İşte bu can diri kalır" (TDV, 2007: 86)

Makâlât'ta insanın kendini bilmesinden bahsedilmektedir. Bunu ehli olmayan kişiler anlamazlar. Kendini bilenler için üç önemli seçenek bulunmaktadır: Dünyayı isteyenler, ahireti isteyenler ve Mevla'yı isteyenler. En doğru olan insanın korku ile ümit arasında olmasıdır.Dünya ve ahiret arasında bir denge kurarken Mevla unutulmamalıdır.

Makâlât'ta dört türlü candan bahsedilmektedir: 1.Can: Cismani can olup bu can diri kalır ve diken batmasını, kıl çekilmesini hisseder. 2.Can: Yeme, içme gibi algıları hisseden bize acıkmayı ve susamayı bildiren candır. 3.Can: Ruhani can dedikleri bu can beden uyuyunca uyanır. Bu can bir bakıma binek hayvana benzer. Bu can soğuk, sıcak, tatlı, acıyı hissetmektedir. Bu anlayışa göre ten canın bineğidir. 4.Can: Bu can kısaca marifettir. Bu can bahçeye benzetilerek açıklanabilir. Su susamış bahçeye ne yaparsa marifet suyu da cana öyle bir etki yapar. Cenabı Hak din ve iman bahçesini bizler için donatmış ve marifet suyunu da gönlümüzdeki bu bahçeye akıtmıştır. Bu bahçe sahipsiz değildir (TDV, 2007).

Ariflerin Tevhidi bölümünde nefs kavramı açıklanmıştır: Dünyada savaşlar yapılmakta ve düşmanlar bulunmaktadır. İşte nefs insanın düşmanıdır ve nefs ile mücadele savaş etmek gibidir. Aksine gönül ise Tanrı'nın bakış yeri olup Allah ile arasında perde yoktur. Müminin 
kalbi Kâbe gibidir. Mümin canını gafletten uyarandır. Dünyada nasıl ki Arş, Kürsi, levh, Kalem, Cennet, Cehennem kavramları görünmezlerse insan vücudunda bulunan us, akıl, ilham, hidayet, fikir, endişe, anlama gibi kavramlar da görünmezler (TDV, 2007).

Cafer-i Sadık buyurur ki:"Hak Teâlâ âdemi yaratmak diledi, meleklere bildirdi... Âdemin yüzünü Medine toprağından yarattı... Cenab-1 Hak 'Âdemi topraktan ve nutfeden yarattım.' buyurdu.Hak Teâlâ'nın emri ve yaratılış azametiyle âdemin gövdesine can girdi ve melekler onu rıza suyu ile yıkadılar. Allah âdeme, 'Yerde gökte halifesin.' dedi. Âdem kalktı oturdu, aksırdı ve 'Her halde Allah'a hamd olsun.' dedi. Bunun üzerine Allah 'Rabbin sana rahmet etsin ey Âdem.'seni bu kelime için yarattım buyurdu.’'(TDV, 2007)

Makâlât’ta, insanın yaratılışı Kur'an'dan ayetlerleaçıklanır: “Erkek hanımına yaklaşınca ondan bir su, hanımından bir su çıkar. İki melek bunları karıştırır. Melekler, 'Ya Rabbi! Bu iki nutfeden insan yaratmak istiyor musun?' diye sorduklarında, Allah Teâlâ 'Yaratacağım ey melekler.' buyurur... Hak Teâlâ'nın görevlendirdiği dört melek bu kişinin açlığını, kötü talihini, rızkını ve başına gelecek olayları yazarlar. Bu nutfeye onuncu gün can girer. Allah anne bağrını çocuğa mihrap kılmıştır. Bu olanlar insansa can verilmesi sebebiyle olur. $\mathrm{Bu}$ yüce işler ona insan olma sebebiyle yapılmaktadır. İnsana, can ile akıl verildiği zaman insan için yaratılış ferman çıkmıştır.’'(TDV, 2007).

Makâlât’ta, veli kişilerin canlarının kolay alındığı, marifet kapısına gelindiğinde, her şeyin canla diriliği,âşıkların teninin öldüğü ama canının ölmediği, kendini bilen insanın Mevla'yı dilemesi, korku ile ümit arasında olması gerektiği belirtilmektedir. Eserde dört türlü candan bahsedilmiştir. Birinci can olmadığında insan ölür. İkinci can yaşamın devam etmesini anlamına gelir. Bu iki can hayvanlarda da bulunur. Üçüncü yani ruhani can ise insanda bulunur. Bu canı taşıyanlar da mükemmel insan sayılmazlar. Onların hayvanlardan tek farkı, Hak yolunu bilmeleridir. Bunların gönül gözü kördür. Gönül gözü kör olanlar hayvanlar gibidirler ve Hak yolunu göremezler. Bu can sahipleri, Hakk'ın sırlarına vakıf olmayan insanlardır. Bu canı taşıyan insanlar görünüşte insan ama davranışlarında hayvan gibidirler. Dördüncü can yani marifet suyu ile sulanmış can, Hakk'1 gören, bilen ve O'nu zikreden candır. Elbette dini ve imanı olan, münâcât ve müşâhede halinde bulunan insanların (canların) bekçisi Allah’tır (TDV, 2007).

\section{Buyruklarda can, ruh ve nefs kavramı}

Şeyh Sâfî Vasiyetnamesi Büyük Buyruk olarak bilinir. İmam Cafer-i Sadık Buyruğu'nun gerçek adı Menakıb-ı Esrar Behçet'ül Ahrar olup, yazarı Bisatî'dir. Bunlardan başka, Sefer Aytekin tarafından hazırlanmış bir Buyruk bulunmaktadır (Kılınç, 2008: 5). Başkalarınca yazılmış buyruklar olsa da bunlar önceki yazılmış olan buyrukların sadeleştirilmiş veya elden geçirilmiş nüshalarıdırlar.

Buyruklarda can kavramı daha çok kadın-erkek farklılı̆̆ını dikkate almama, yani birisini insan olarak görme anlamında kullanılmıştır. "Mürebbiye ve musahibe razı olmayan talipler hakikate razı olmazlar. Hakikat ehli canların onları hakkın halkasına koymamaları gerekir." cümlesinde olduğu gibi (Bozkurt, 2011: 60). Musahip musahibiyle bir evde, bir köyde veya 
bir şehirde olmalıdır. Bunların dışında olması erkân değildir. Zira musahip cesettir, erkân candır. Can cesetten dışarı çıksa ölür.” cümlesinde ise bir benzetme yapılmıştır. Yani musahip olan kişinin yol ve erkâna uymasının gerekliliği vurgulanmıştır. Bunların birbirinden ayrı olması düşünülemez mesajı verilmek istenmektedir.

Buyrukta ruh ve can kavramına 1şık tutacak bir anlatım, “yol ve erkân, dört kapı” başlığı altında yapılmıştır: “..Hâlık-1 âlem kudretini aşikar kılmak diledi....yer, gök, güneş, ay, yıldızları, bütün bunları yarattığında, kemali kereminden lütfu inayetinden bir yeşil derya yarattı. O deryaya nazar buyurdu. Derya dalgalandı, coşa geldi ve bir cevheri dişarıya düşürdü. Hak Celle ve âlâ bu cevheri aldı. İki şak eyledi. Parçalar biri yeşil, biri ak nur oldu. Yeşil kubbe misali bir kandil asılı durmaktaydı. Allah Teâlâ bu nurları bu kandile koydu. Yeşil nur Muhammed Mustafa'nın, ak nur da Murtaza Ali’nin nuru oldu ki bunlar bütün ruhların kadimi idi”(Vaktidoldu, 2011: 251-252).

Buyruğun bu kısmında yaratılan ilk nurun Muhammed ve Ali nuru olduğu ve Cenabı Hak bunu kudretini aşikâr kılmak için yarattığı belirtilmektedir. Bir hadisi kutsi bu açıklamayı doğrulamaktadır (Acluni, Keşfü'l-Hafa, II/132; Akt, Başar, 2006). Buyrukta bu açıklamadan sonra dört büyük meleğin yaratılması ve Azâzil'in (şeytan) bu nurlara secde etmemesi anlatılmıştır. Hatta Azâzil'in bu nurlara tükürdüğü ve bunun bir halkaya dönüşerek onun boynuna geçtiği anlatılır.

Buyrukta yaratılışla ilgili kısım şöyle devam etmektedir: "Melekler, levh, kalem, arş, cennet, cehennem, gökler, arzın hilkatinden üç yüz yirmi dört bin yıl önce, kabza-i kudretle (kudret eli) cemal-i nurundan, Hak Teâlâ bir avuç nur kabzeyledi (aldı) ki Muhammed Ali’nin nurudur.Muhammed ve Ali'nin nurları ilk yaratılanlardır. Allah onların nurunu kendine secde ettirdi. Dünya yıllarıyla yüz yirmi dört bin yıl secde emrinde Hakka hizmet ettiler. Müteakiben Muhammed Ali'nin lem'asından (parıltısından-nurundan) bir inci yaratıldı ki bu iki nur burada karar kıldı. Bu âleme “Âlem-i Umman” derler.” (Vaktidoldu, 2011).

Buyrukta Allah Teâlâ'nın kendi nurundan Muhammed ve Ali’nin nurunun yaratıldığı belirtilmiştir. Bunların ilk yaratılanlar olduğu bildirilmektedir. Bu nurlar Allah'a secde eden ilk nurlardır. Burada belirtilen 124 bin sayısı ilginçtir. Dünyaya 124 bin nebi geldiği söylenir. Bu peygamberler Hakk'a secde etmiş ve Hakk’’n emrini ümmetlerine bildirmiş kişilerdir. Bu sayı ile bu durum anlatılmak istenmiş olabilir. Daha önemlisi Muhammed Ali'nin nurundan bir inci yaratıldığını ve buraya Âlemi Umman dendiğini öğreniyoruz. Umman büyük, engin, deniz anlamına gelmektedir. Yani büyük âlem gibi bir anlama gelmektedir.

$\mathrm{Bu}$ âlem-i ummanda melekler ve diğer mahlûklar yaratılmadan önce Cenab-1 Hak biri diğeri üstüne yetmiş bin şehir halk etti. Bunlar o kadar büyüktü ki genişliği arzın yetmiş misli büyüklügü kadardı. Her bir şehirde yetmiş bin mahlûk yerleşmiş idi. Bu mahlûklar melekler ve diğer gayri yaratılmışlardan farklıydılar. Bütün bunlar Allah'ın Kün (ol) demesiyle olmuştu. Sonra Allah beni âdem suretinde yüz yirmi bin cism-i latif halk eyledi ki Âdem ve meleklerden evveldir. Bunların her birine seksen bin yıl ömür takdir buyurdu. Bunlar da gelip geçti ve son buldu. Gene vücudu âlemde Muhammed ve Ali'nin ruhu kaldı (Vaktidoldu, 2011). 
Buyrukta insanlar ve melekler yaratılmadan önce Allah'ın farklı mahlûklar yarattığından bahsedilmektedir. Allah'ın bir şeyin olmasını istediği zaman "ol” demesinin yeterli olduğu Kur'an-1 Kerim'de belirtilmektedir (Yasin, 82. ayet). Bu yaratılanların Hakkın emrinden dışarı çıktığında onları helak etmesi, Âdem peygamberden günümüze kadar olan zamanda da bazı peygamberler döneminde olmuş vakalardır. Nuh Tufanı, Lut ve Samut kavminin yok olması gibi. Burada kuş kıssası ile anlatılmak istenen şey “kanaat” kavramıdır.

Buyrukta, Cenabı Hakkın insandan başka mahlûklar yarattığından bahsedilmektedir. Yani Allah'ın sonsuz hikmet sahibi olduğu, O'nun zaman ve mekândan münezzeh bir varlık olduğu vurgulanmaya çalışılmıştır. Bu âlemin yaratılış sırrının Muhammed-Ali olduğunun bir kez daha altı çizilmiştir. Levlâke levlâke, Lemahalaktül-eflâk (Sen olmasaydın Ben âlemi yaratmazdım sözü; İslâm ümmetinin ekseri âlimlerince kudsî hadis olarak kabul edilmektedir (Dinimiz İslam, 2017). Alevi inancında, bu hadisin hükmü biraz genişletilmiş, yeryüzünün Muhammed-Ali, bazı kaynaklarda ise Beş Esmanın (Muhammed, Ali, Fatima, Hasan, Hüseyin) yüzü suyu hürmetine yaratıldığı düşüncesi hâkim olmuştur.

\section{Kur'an-ı Kerim'de can, ruh ve nefs kavramı}

Kur'an-1 Kerim'de can kavramı yerine ruh sözcügü geçmektedir. Bunların ne anlama geldiği konusunda farklı görüşlere rastlanmaktadır. Kur'an-1 Kerim’de içinde ruh sözcüğü geçen bazı ayetler şunlardır (KuranFihristi.net, 2009).

“...onu Ruhu'l-Kudüs'le teyid ettik...” (Bakara/87).

“...Böylece ona ruhumuz (Cibril’i) göndermiştik...” (Meryem/17).

“...Böylece Biz ona ruhumuzdan üfledik...” (Tahrim/12).

“Melekler ve ruh, onda Rablerinin izniyle her bir iş için inerler.” (Kadir/4).

"Sana ruhtan sorarlar; de ki: "Ruh, Rabbimin emrindendir..." (İsra/85).

"Ruh ve meleklerin saflar halinde duracakları gün...”( Nebe/38).

“Kullarından dilediklerine, melekleri emrinden olan ruh ile indirir...”(Nahl/2).

“...ona ruhundan üfledi...” (Secde/9).

“Böylece sana emrimizden bir ruh vahyettik...”( Şura/52).

“...ona Ruhum’dan üfürdüğümde hemen ona secde ederek (yere) kapanın.” (Hicr/29).

“Allah, ölecekleri zaman canlarını alır;... kendisi hakkında ölüm kararı verilmiş olanı(n ruhunu) tutar..." (Zümer/42).

“...Biz ona Kendi ruhumuzdan üfledik, onu ve çocuğunu insanlığa bir ayet kıldık. (Enbiya/91).

“...Kendi emrinden olan ruhu kullarından dilediğine indirir. (Mü’min/15).

“...Kendinden bir ruh ile desteklemiştir...” (Mücadele/22).

Kur'an-1 Kerim'de geçen bu ruh sözcüklerinin bazılarının manası zaten bazı meallerde parantez içinde verilmiştir. Bununla birlikte farklı meallerde ruh sözcügüne farklı anlamların 
yüklenmektedir. Kur'an'da ruh kelimesinin vahiy anlamında (İsra,17/85, Mücadele, 58/22); Cebrail anlamında (Nahl,16/102, Meryem, 19/17, Enbiya, 21/91, Şuara, 26/193, Tahrim, 66/12, Mearic, 70/4, Nebe, 78/38, Kadir, 97/4); Kur'an anlamında (Nahl,16/2, Mümin, 40/15, Şûra, 42/52); Cebrail ya da vahiy anlamında (Bakara, 2/87, 253, Maide, 5/110, Nahl, 16/102); insan1 yaşatan can anlamında (İsra, 17/85) kullanıldığı düşünülmektedir (Merdin, 2014).

Bu ayetlere farklı bir yorum getiren Çelik (2017), temel kaynak olarak Hakkı Yılmaz'1 (Tebyinül Kur'an) göstererek, Kur'an ayetlerinde geçen ruh sözcügünün bilgi anlamına geldiğini ve ayetlerin insana verilen bilginin “can ve ruh katar” biçiminde anlaşılması gerektiğini belirtmektedir.

\section{Alevi deyişlerinde can, ruh ve nefs kavramı}

Tasavvuf Terimleri ve Deyimleri sözlüğünde deyiş şöyle tanımlamaktadır: Alevî-Bektaşî edebiyatında, çoğunlukla hece vezniyle söylenmiş şiirlere deyiş adı verilir. Bektaşiler bu tür şiirlere, genellikle "nefes" derken, Alevîler "deyiş" der. Bâtıni inanç sebebiyle, ayet diyenler de vardır (Cebeci (2009: 64). Bu deyişlerin çoğunluğu Türkçe olup, hayatın birçok alanındaki konulara açıklık getirir. Yedi ulu ozanın söylediği deyişler, Alevi inancında yazılı kaynak olarak kabul edilir (Gül, 2014: 125). Yedi ulu ozan; Nesimi, Yemini, Fuzuli, Şah İsmail Hatayî, Viranî, Pir Sultan Abdal, Kul Himmet’tir (Dönmez, 2014: 10). Bu kişilerin can ile ilgili birçok deyişi bulunabilir. Ancak bunlardan birkaç örnek ile yetinilmeye çalışılmıştır.

Eğer aslım sorarsan ben bir niyazım

Sabır ilmi derler yerden gelirim

Ve katre (damla) idim simdi umman oldum

Aşktaki kandilden nurdan gelirim (Seyit Nesimi, 2017)

Mürşidin nazarı müşkülü seçer

Kâmil olan talip sıratı geçer

Can kuşu kafesten akıbet uçar

Tenden uçan candan rehber isterler (Pir Sultan Abdal, 2017)

Bir gün seni götürürler evinden

Hakkın kelamını kesme dilinden

Kurtulmazsin Azrail'in elinden

Türlü türlü yolun olsa ne fayda (Kul Himmet, 2017)

Bir gerçeğin eleğinde elendim

Beli dedim beli 'sine belendim

Arşı kürsü yaratandan dilendim

Âdem olup erkânına eriştim (Virani, 2017) 
Can verme sakın aşka aşk afeti candır

Aşk afeti can olduğu meşhuru cihandır (Fuzuli, 2017)

Men nice terk eyleyem hüsnü cemalin bilmezim

Çünkü sensin can içinde can ü hem cananımız (Yemini, 2017)

Erenler cemine her can giremez

Edep ile erkân yol olmayınca

Her kamberim diyen kamber olamaz

Şahın kamberine kul olmayınca (Şah Hatayi, 2019)

Alevi deyişleri bu yedi ulu ozanla sınırlı değildir. Bunların dışında can, ruh ve yaratılış ile ilgili deyişlere rastlanmaktadır. Bu deyişlere de birkaç örnek verilmiştir. En meşhur olanı, Hamdullah Çelebi'nin on altı kıta söylediği ve insanın yaratılışını anlatan deyişidir ki iki kıtası aşağıda verilmiştir:

Cihan var olmadan ketm-i âdemde

Hak ile birlikte yek taş idim ben

Yarattı bu mülkü çünkü o demde

Yaptım tasvirini nakkaş idim ben

Hamdulillah şimdi Şiri dediler

Geldim gittim zatım hiç bilmediler

Kimseler bu remzi fehim etmediler

Her gelen mahlûka kardeş idim ben (Âşık Remzâni, 2017)

Yaratılışın sırlarını anlatan bir başka deyiş Seyrani tarafından dile getirilmiştir. Bu deyiş aynı zamanda buyruklarda bahsedilen, evreninin yaratılışı kıssasını açıklar niteliktedir:

Seyranî’yim buldum aşkın arısın

Kadrini bilmezse vermem yarısın

Bir kuşa seksen bin şehrin darısın

Rızık verilirken yanında idim (Seyrani, 2017)

\section{Alevi cemlerinde can, ruh ve nefs kavramı}

Can, Alevi cemlerinde kullanılan en önemli hitaplar arasında yer alır. Cem ibadetine katılan kişilere hitap edilirken genellikle dede, "canlar" diye başlar. Bunun anlamı kadınerkek herkesi bir görmektir. Yani cem erkânında kişinin cinsiyeti önemsenmez. Kırkların cemi olarak tabir edilen ve Hz Muhammed'in ancak "ben bir fukarayım" diyerek girdiği cem evinde, 17 kadın 23 erkek canın olduğu bilinmektedir (Vaktidoldu, 2011: 17). 
Kadın-erkek bir arada yaşama anlayışını inançtan öte, eski Türk geleneğine dayandıranlar bulunmaktadır. Hunlar döneminden itibaren kadın-erkek ayrımı yapılmamış ve kadın erkeğin tamamlayıcısı olarak görülmüştür. Göktürklerde ve Uygurlarda, kağanın karısı hatun, devlet işlerinde kocasıyla birlikte söz sahibi konumunda olmuştur. Türk destanlarında kadın daima erkeğinin yanındadır. Onların güç ve ilham kaynağıdır (Gündüz, 2012: 131-133). İslam öncesindeki bu yaşam biçiminin Alevi Türkmenlerde aynı kaldığı söylenebilir.

Hacı Ahmet Yesevi tasavvufla uğraşan bir Türk dervişi olup, sohbetlerini kadın-erkek bir arada yapmaktaydı (Onat, 2017). Bu nedenle bulunduğu coğrafyada eleştirilmiştir. Onun düşünceleriyle yetişmiş birçok derviş farklı yerlere giderek bu felsefeyi hayata geçirmeye gayret etmişlerdir. Onun müritlerinden olan Lokman-1 Parende, Hacı Bektaş Veli'nin hocasıdır. Hacı Bektaş Veli'nin öğretisinde de Anadolu'da kadın-erkek, sen-ben ayrımı yapılmaksızın birlikte ibadet etme anlayışı varlığını korumuştur. Ancak Sünni İslam anlayışını benimseyen Türkler, kadın-erkek birlikte ibadet etme anlayışını bir türlü benimsememiş veya benimsemek istememişlerdir. Hacı Bektaş Veli’ye göre, "Muhabbetin dilinde erkek dişi sorulmaz" ve "Kadın ve erkek arasında fark gözetmek bir eksiklik ve noksanlık belirtisidir.

Cem, tarikat ehli kişilerin yaptığı bir ibadet biçimidir. Yani bu ibadet, Hacı Bektaş Veli öğretisinde ikinci, yani Tarikat kapısı içinde yer almaktadır. Bu ibadetin birinci, yani Şeriat kapısındaki karşılığı namaz olup, kadın ve erkeklerin ayrı yerlerde ibadet etmelerini gerektirir. Hacı Bektaş Veli'ye göre, bu kapıdaki kişiler ham Müslümandırlar. Bu taifede büyüklenme, kıskançlık, nefret, cimrilik ve düşmanlık her an görülür (TDV, 20074: 47). Alevilikte eline, diline ve beline sahip olma etik kuralı, düşkünlük ve musahiplik gibi kurumlar kadın-erkek ilişkilerine farklı bir boyut getirmiştir. Bu bakımdan kadın ve erkeklerin birlikte ibadet etmelerinde bir sakınca görülmez. Alevilerin ibadet yerlerinde (cem evinde), cinsiyet ayrımı yapılmaksızın herkes can olarak görülür.

\section{Nefsin eğitimi}

Yapılan açıklamalardan ruhun nuranî, nefsin ise şeytanî bir varlık olduğu, ruhun akıl ile hareket ettiği, nefsin ise vücudun arzu ve istekleriyle ilişkili olduğu anlaşılmaktadır. Ruh, dünyada biyolojik bedeni idare ederken en çok akıldan destek almaktadır. Birey böylece iradesini kullanabilmektedir. İnsan hayatı son bulduğunda ruh kafesten uçmakta ve sahibinin hayatı boyunca yaptığı işlerin kayıtlarıyla birlikte, berzah âleminde yaşamını devam ettirmek üzere yola çıkmaktadır. Bu durum kısaca, ölüm, Alevi inancında ise "Hakk'a Yürüme” olarak nitelendirilmektedir (Uluocak, 2014: 59).

Ruh, insana hep iyiliği emrettiğine göre, onun eğitilmesi gereksizdir. Can, insana hareketlilik kazandıran ve ruhun emriyle hareket eden bir varlık olduğundan onu da eğitmek gereksizdir. Böylece geriye nefs kalmaktadır. O halde eğitilmesi gereken de odur (Kıray, 2013; Hucviri, 1982; Sivasl1, 2016; Nurefşan, 2011). Diğer canlılar değil de "Niçin insan böyle bir sınava tabi tutulmaktadır?" sorusu aklımıza gelebilir. Bunun nedeni insana akıl ve irade verilmesiyle açıklanabilir. İnsanın aklını ve iradesini kullanma yeteneği bulunmaktadır. Yaratılışı itibariyle o bir yüceliğe sahiptir, yeryüzünün halifesidir. Onun için insan nefsini köreltip ruhunu güzelleştirmelidir. Bu ise bir eğitimle mümkün olabilir. 
Alevi inancında nefsin eğitimi önemli yer tutar. Bu eğitimin ilk aşaması bir pirden el tutmaktır. Bu eylemi işlenen günahlara tövbe etme işi takip eder. Bu yola başını koyan (saç kesme) kişi, nefsini olgunlaştırır, talip (mürit) olup halka hizmet eder. Ümit ve korku arasında, hidayete ermek için nasihat ve muhabbet sahibi olmaya özen gösterir. Allah'1n büyüklüğü karşısında özünü fakir görür (TDV, 2007: 30). Alevi inancında, eline, diline ve beline hâkim olma (EDeB) inancın temel esaslarından birisidir (Gül, 2016: 99). Bunlara ilaveten üç sünnet, yedi farz, düşkünlük, başkalarından razı olma, musahiplik gibi kurumlar nefsi eğitmenin başka yolları olarak karşımıza çıkmaktadır (Gül, 2014). Bu bağlamda Alevi inancında nefsin eğitiminin önemli bir yer tuttuğu görülmektedir. Hacı Bektaş Veli'nin zahitler olarak nitelediği kişiler, dünyada ahiret için yararlı işler yaparlar (Coşan, 1996: 3).

\section{Sonuç}

Can ve ruhun aynı şeyler olduğunu savunan araştırmalar olduğu gibi bunların farklı kavramlar olduğunu kabul eden araştırmalara da rastlanmaktadır. Başka bir önemli mesele de ruh ile beden ilişkisidir. Mevlana, ruhu bedenin hareketleriyle bil derken, ruhsuz bir bedenin olamayacağını belirtmek istemektedir. Bazı çalışmalarda ise ruh manevi cevher (enerji) veya enerji formu olarak görülmektedir. Kısacası, ruhun ne olduğuna ilişkin farklı açıklamalar bulunmaktadir.

Kur'an'da ruhun ne olduğu hakkında açıklamaya yer verilmemiştir. Allah bizim sınırlı duyularımızla ruhu anlayamayacağımızı bildiği için insana bu konuda az bilgi verilmiştir. İnsanoğluna bilmedikleri ancak bildiği kavramlarla anlatılabilir. İnsan bilmediği kavramlarla bir şeyi tasavvur edemez. Nur kelimesi ne demektir? Işık mıdır? Enerji midir? Bu bakımdan can ve ruh ile ilgili bir açıklama yapılacaksa, bunun bilinen kavramlarla yapılması gerekir. $\mathrm{Bu}$ ilişki bir bilgisayar örneği ile açıklanabilir. Bu durumda nasıl tek bir program ile birden fazla bilgisayar işletiliyor ise bir tek ruhla bütün insanlar idare edilebilir. Böylece Allah ademe ruhundan üfledi sözünün anlamı daha iyi anlaşılır. Elbette bu programları kullanan kişiler bunu iyi veya kötü amaçlı kullanabilirler. Mutlak güç sahibi Allah için bunu yapmak kolaydır.

Şüphesiz can ve ruh kavramı bu örnekteki kadar basit değildir. Her şeyden önce bilgisayar insan yapımıdır. Belki anlamayan birisine karmaşık gelebilir ama Allah'ın kendi cevherinden yarattığı ruh ve can kadar karmaşık değildir. Diğer yandan biyolojik bir sistemi mekanik bir sistemle açıklamak da doğru olmaz. Ruh ve can kavramı hakkında bu kadarının bilinmesi, elbette bizim için daha hayırlı görülmektedir. Bilmemiz istenseydi, yüce Rabbimiz bu konuda bize daha fazla bilgi verirdi. Bu konuda peygamberlere ve velilere daha fazlas1 verilmiş olabilir. Musa ile Hızır arasında geçen kıssa buna güzel bir örnek teşkil etmektedir. Hızır'a verilen ilim, Musa peygambere verilmemiştir.

Bu tartışmadan sonra şu sonuçlara varılabilir: Ruh ve can kavramları karmaşık olup, bu konuda insanoğluna çok az bilgi verilmiştir. Bu husus Kur'an ayetlerinde de belirtilmiştir. Kanaatimize göre, ruh ve can birbirinden ayrı kavramlardır. İnsan önce ana rahminde canlıdır ancak ona daha sonra ruh üflenir. Canlı olan her varlığa bir can ve türüne göre bir ruh 
verilmiştir. Yaratılanlar içinde insan akıllı olduğu için bu ruhu en iyi şekilde kullanır. Kâmil insan canı, marifet suyu ile sulamıştır. Eğer insan nefsi arzularının esiri olursa, ruh bundan rahatsiz olur.

İnsana kötülükleri fark edip savaşabilmesi için akıl verilmiştir. İnsan aklını ve iradesini kullanarak iyi veya kötü yönde davranışlarda bulunabilir. Allah, insanı ruh ve nefis gibi birbirine iki zıt varlıkla imtihan etmektedir. İnsan nefsin aşırı isteklerine karşı çıkabilirse ruhunu yüceltmiş ve Hakk'a yaklaşmış olur. Allah insanlara neyin iyi neyin kötü olduğunu peygamberleri ve kitapları aracılığıyla bildirmiştir. Ruh ve can kavramı bazı kaynaklarda aynı anlamda kullanılırken, Kur'an' da bilgi anlamda kullanılmıştır. Alevi deyişleri can kavramına açıklık getiren önemli kaynaklardır. Türkçe oldukları için daha kolay anlaşılmaktadırlar. Aleviler, cem evinde ruhu yüceltmek ve nefisle mücadele etmeyi güçlendirmek için deyişler söylerler. Yedi ulu ozanın deyişlerinden örnekler verilir. Dede bu deyişlerle ilgili nasihatler ederek canları ruhen temiz olmaya davet eder. Kur'an-ı Kerim başta olmak üzere, İmam Cafer Buyruğu gibi kaynaklardan da yararlanılır. Hacı Bektaş Veli’nin Makâlâtı ve diğer eserleri de temel kaynak olarak kullanılır.

\section{Kaynaklar}

Ahmet H.(2014). Ruh insan cin. İstanbul: Kitsan.

Altıntaş, R.(2017). İslâm itikadına göre rûh ve mâhiyeti. Somuncu Baba Dergisi, 201, 14-17.

Atay, H.(1997). Nefis. Ankara Üniversitesi IIlahiyat Fakültesi Dergisi. 37 (1), 1-58.

Bağçeci, M.(1987). Ruhun muhtaç olduğu şey imandır. Erciyes Üniversitesi İlahiyat Fakültesi Dergisi, 5 (4), 179-209.

Bayrakl1, B.(1986). Eğitim felsefesinde idealizm. Marmara Üniversitesi İlahiyat Fakültesi Dergisi. 4, 185-217.

Cengil, M. (1996). Kur'an-ı Kerim 'deki nefs kavramına psikolojik açıdan bir yaklaşım. Yayımlanmamış yüksek lisans tezi, Ondokuz Mayıs Üniversitesi, Samsun.

Coşan, E.(1996). Makâlât. Ankara: Kültür Bakanlığı.

Çebi, A. (2019). İslâm kültüründe nefs kavramı. Yayımlanmamış yüksek lisans tezi, Ondokuz Mayıs Üniversitesi, Samsun.

Mustan Dönmez, B. (2014). Sufilik algısının “Türk yöresel müziği” sözlerindeki varlığı, Alevilik Araştırmaları Dergisi, 4(8), 1-11.

Gül, İ. (2014). İtikat, amel ve ahlak bağlamında Alevi-Bektaşi ve Sünni inançların karşılaştırılması. Alevilik Araştırmaları Dergisi, 8, 117-130.

Gül, İ. (2016). Kentleşme sürecinde Anadolu Aleviliğinin bazı temel sorunları ve çözüm önerileri (Samsun ili örneği). Alevilik Araştırmaları Dergisi,12, 95-111.

Gül, İ. (2014). Bir sosyal sistem olarak Alevilik. Hünkâr Alevilik Bektaşilik Akademik Araştırmalar Dergisi, 1, 67-82.

Gündüz, A.(2012). Tarihî süreç içerisinde Türk toplumunda ve devletlerinde kadının yeri ve önemi. Jasss International Journal of Social Science, 5(5),129-148. 
Hallaçi, B. (2013). Plotinus ve Fârâbî'de ruh/nefs kavramı. Yayımlanmamış yüksek lisans tezi, Bursa Uludağ Üniversitesi.

Hucvirî (1982). Hakikat bilgisi, S. Uludağ (Çev.). İstanbul: Dergâh.

Kantik, E. (2015). Tefsîru'l-Ceylânî'de nefs kavramı. Yayımlanmamış yüksek lisans tezi, Kayseri: Erciyes Üniversitesi.

Kılınç, A. (2008). Alevî-Bektaşî geleneğinde vasiyet ve buyruk üzerine. Türk Kültürü ve Hacı Bektaş Veli Dergisi, 45, 83-92.

Kuşeyrî, A. (1978). Risâle-i Kuşeyriyye, S. Uludağ (Çev.). İstanbul: Dergâh.

Müslim (1998). Ebü’l-Hüseyin el-Kuseyri en-Nişaburi Müslim b. el-Haccac, Sahihu Müslim, Riyad, Beytül el-Efkareddevliyye'

Osman, B., M. (2017). Gazzali'nin ahlâk felsefesinden nefs kavramı. Yayımlanmamış yüksek lisans tezi, İstanbul Üniversitesi, İstanbul.

Ögke, A. (1994). Kur'an'da nefs kavramı. Yayımlanmamış yüksek lisans tezi, Selçuk Üniversitesi, Konya.

Özdemir, C. (2017). Hak âşı̆̆ı Amasyalı Fedâî Baba ve tasavvuf kültürü. Türk Kültürü ve Hacı Bektaş Veli Dergisi, 83, 125-148.

Özkan, Ö. (2010). Can ve ten kavramları bağlamında garib-nâmede insana bakış. Türk Kültürü ve Hacı Bektaş Veli Araştırma Dergisi,55, 357-370.

Taş, C. (1994). Tasvvufta ruh kavramı. Yayımlanmamış yüksek lisans tezi, Atatürk Üniversitesi, Erzurum.

TDV (2007). Makâlât. A. Yılmaz, M. Akkuş ve A.Öztürk(Haz.), Ankara: Türk Diyanet Vakfı

Ucatlı, A. (2009). İslâm hukukunda cenine müdahalenin hükmü. Yayınlanmamış yüksek lisans tezi, İstanbul Üniversitesi, İstanbul.

Uluocak, Ş. (2014). Kazdağı Tahtacı Türkmen kozmolojisinde "hakka yürümek”. Türk Kültürü ve Hacl Bektaş Veli Araştırma Dergisi, 71, 55-82.

\section{Elektronik kaynaklar}

Acar, E.(2018). Bilgisayarın tanımı ve donanım bilgisi. Erişim adresi: http://yunus.hacettepe. edu. $\mathrm{tr} / \sim$ eacar/dersler/uygulamalar/bilgisayar.pdf 10.2.2020 tarihinde erişildi.

Arkut, E.(2014). Ölüm anında neler yaşayacağız? Erişim adresi: https://erkanarkutyaziyor.wordpress. $\mathrm{com} / \mathrm{tag} / \mathrm{ruh}$-bedenden-nasil-cikar/ 10.2.2020 tarihinde erişildi.

Aşık Remzâni (2017). Yorumu ile pir dergâhından nefesler. Erişim adresi: http://www.asikremzani.net/ makale/bektas_celebi_devriye.html 10.2.2020 tarihinde erişildi.

Ateş, S.(2017). İsra suresi, 85. Ayet. Erişim adresi: http://www.kuranmeali.org/17/isra_suresi/85.ayet/ kurani_kerim_mealleri.aspx 11.2.2020 tarihinde erişildi.

Başar, A.(2006). Ruh nedir, ruhun mahiyeti anlaşılabilir mi? Ruh beyinden mi ibarettir? Erişim adresi: https://sorularlaislamiyet.com/ruh-nedir-ruhun-mahiyeti-anlasilabilir-mi-ruh-beyinden-miibarettir 10.2.2020 tarihinde erişildi.

Bigalıoğlu, M.(2009). Ruh nedir? Erişim adresi: http://www.bilimfelsefedin.org/?p=582 
Bozkurt, .(2011). İmam Cafer Buyruğu. Erişim adresi: https://tr.scribd.com/document/352826074/ Fuat-Bozkurt-Buyruk-\%C4\%B0mam-Cafer-i-Sad\%C4\%B1k-Buyru\%C4\%9Fu-b-pdf 11.2.2020 tarihinde erişildi.

Cebeci, E.(2009). Tasavvuf terimleri ve deyimleri sözlüğü. Erişim adresi: http://tasavvufkitapligi.com/i/ uploads/429779tasavvuf-terimleri-ve-deyimleri-sozlugu.pdf 10.2.2020 tarihinde erişildi.

Çelik, Z. (2017). Ruh. Erişim adresi: http://zekicelik.com/topic-etail? Konu= c4meTRYGsFK1oxDxTbmIiH 13.2.2020 tarihinde erişildi.

Dinimiz İslam (2017). Sen olmasaydın kâinatı yaratmazdım. Erişim adresi: http://www.dinimizislam. com/detay.asp?Aid=406 10.2.2020 tarihinde erişildi.

Fuzuli (2017). Aşka sevdalanma. Erişim adresi:https://www.antoloji.com/aska-sevdalanma-siiri/ 13.2.2020 tarihinde erişildi.

TDK (2017). Can ve ruh kavramı, Erişimadresi: http://www.tdk.gov.tr/index.php?option=com_gts 10.2.2020 tarihinde erişildi.

Kaptan, R.(2014). Candaş aleviler ve Alevilik hakkında sohbetler. Erişim adresi: http://www. alevitentum.de/Candaslik.pdf 14.2.2020 tarihinde erişildi.

Kul Himmet (2017). Gafil gezme şaşkın. Erişim adresi: https://www.antoloji.com/ gafil-gezme-saskin3-siiri/ 10.2.2020 tarihinde erişildi.

KuranFihristi.net (2009). Ruh ile ilgili ayetler... Erişim adresi: http://www.kuranfihristi. net/ayetleri/ruh 12.2.2020 tarihinde erişildi.

Merdin, S.(2014). Rabbine dönen ruh mu? Nefis mi? Erişim adresi: https://mehmetselvi. wordpress. com/2014/02/06/rabbine-donen-ruh-mu-nefis-mi-saadettin-merdin/ 11.2.2020 tarihinde erişildi.

Mevlânâ (2017). Mevlânâ Celâleddîn-i Rûmî/ruh. Erişim adresi: https://tr.wikiquote. org/wiki/ Mevl $\%$ C3\%A2n\%C3\%A2_Cel $\%$ C3\%A2ledd $\%$ C3\%AEn-i_R\%C3\% BBm\%C3\%AE/Ruh 11.2.2020 tarihinde erişildi.

Nurefşan (2011). Tasavvufta ruh ve ceset kavramı. Erişim adresi:http://brbuketnur. Blogspot.com. $\operatorname{tr} / 2011 / 09 /$ tasavvufta-ruh-ve-ceset-kavrami.html 10.2.2020 tarihinde erişildi.

Onat, H.(2017). Ahmet Yesevi'nin din anlayışı ve Bektaşilikteki bazı yansımaları. Erişim adresi: http:// www.hasanonat.net/index.php/89-ahmet-yesevi-nin-din- anlay-s-ve-bektasilikteki-baz-yansmalar 14.2.2020 tarihinde erişildi.

Pir Sultan Abdal (2017). Mürşide varmaya talip olursan deyişi, Erişim adresi: http://www.siir.gen.tr/ siir/p/pir_sultan_abdal/murside_varmaya_talip_olursan.ht 14.2.2020 tarihinde erişildi.

Seyrani (2017). Kuran yazılırken arş-ı rahmanda. Erişimadresi:https://www. antoloji. com/kuranyazilirken-ars-i-rahmanda-siiri/ 10.2.2020 tarihinde erişildi.

Seyyid Hakk1 (2017). Alevilikte can hitabı ve kelime manası. Erişim adresi: https://www.uludivan. de/Alevilikte-CAN--hitab\%26\%23305\%3B-ve-kelime-manas\%26\%23305\%3B.htm 10.2.2020 tarihinde erişildi.

Seyyid Nesimi (2017). Alevilikte çerağ nedir? Erişim adresi:http://www. aleviislamdin hizmetleri.com/ pages/haftalik-sohbet/24/cerag 9.2.2020 tarihinde erişildi.

Sivasl1, A.(2016). Tasavvufí düşüncede ruh ve nefs. Erişim adresi: http://yenidunya dergisi. com/ tasavvufi-dusuncede-ruh-ve-nefs/ 10.2.2020 tarihinde erişildi. 
Şah Hatayi (2019). Şah İsmaili Safevi (Şah Hatayi). Erişim adresi: https://www.deyisler-nefesler.com/ sah-hatayi/ 9.2.2020 tarihinde erişildi.

Tomor A.(2016). Ruh nedir ? Nasıl bir varlıktır? Erişim adresi: 26.12.2017. http://www.ihvanlar. net/2016/07/12/ruh-nedir-nasil-bir-varliktir/10.2.2020 tarihinde erişildi.

Virani (2017). La mekan ilinden geldim cihana. Erişim adresi: https://www.antoloji. Com/la-mekanilinden-geldim-cihana-siiri/?siralama $=\mathrm{p}$

Yemini (2017). Ey saçı küfr-i siyah-ü vey ruh-i imanımız. Erişim adresi: https://www. antoloji.com/eysaci-kufr-i-siyah-u-vey-ruh-i-imanimiz-siiri/?siralama $=$ p 10.2.2020 tarihinde erişildi. 